DOCTRINA

\title{
Inteligencia artificial en la relación médico-paciente: Algunas cuestiones y propuestas de mejora
}

\author{
Artificial intelligence and civil responsibility in the doctor-patient relationship: \\ Some questions and proposals for improvement
}

\author{
Francisca Ramón Fernández \\ Universitat Politècnica de València, España
}

\begin{abstract}
RESUMEN La inteligencia artificial y su aplicación en la medicina cambia las premisas de la relación médico-paciente como la conocemos. La creación de robots médicos y la existencia de aplicaciones informáticas en las que las nuevas tecnologías de la información y comunicación son el eje principal de su actuación determinan que se revise la relación entre la máquina y el paciente. Para abordar estos contenidos, reflexionaremos sobre robótica y la escasa normativa comunitaria aplicable, para aportar algunas claves sobre la denominada personalidad electrónica, además de la responsabilidad civil por daños causados por los robots en el ámbito médico.
\end{abstract}

PALABRAS CLAVE Inteligencia artificial, algoritmos, legislación, medicina, paciente.

ABSTRACT Artificial intelligence and its application in medicine change the premises of the doctor-patient relationship as we know it. The creation of medical robots and the existence of computer applications in which the new information and communication technologies are the main axis of their action determine that the relationship between the machine and the patient is reviewed. To address these contents, we will reflect on robotics, and the scarce applicable community regulations to provide some clues about the so-called electronic personality, and civil liability for damages caused by robots in the medical field.

KEYWORDS Artificial intelligence, algorithms, legislation, medicine, patient. 


\section{Introducción}

Las nuevas tecnologías de la información y comunicación (TIC) han irrumpido en todos los órdenes de la vida. El avance tecnológico hace posible situaciones y escenarios que nadie había podido imaginar (Martínez Devia, 2019: 5), nada más que en una película de ciencia ficción. Nuestra vida cotidiana ya no se concibe sin los instrumentos y herramientas fruto de una tercera revolución industrial, la revolución tecnológica y digital.

La utilización de robots en el ámbito doméstico (robots de cocina, robots para la limpieza) se consideran hoy como algo usual y una ayuda en las tareas habituales. Sin embargo, cuando nos planteamos extrapolarlo a otros ámbitos en los que un robot puede tomar decisiones que afecten a nuestra vida y salud, o bien establecer relaciones interpersonales con ellos, la cuestión ya adolece de algunas fisuras y nos genera, por regla general, desconfianza e inquietud. Estamos en presencia de la inteligencia artificial aplicada al acto humano.

En la época actual, en la que nos encontramos sumidos en una crisis sanitaria por el covid-19, la presencialidad en el ámbito médico se ha reducido de forma considerable. Se ha sustituido la visita médica al centro de salud, sobre todo en el caso de atención primaria, por la atención telefónica. Muchas compañías privadas de aseguramiento en salud han optado por la denominada telemedicina o e-health para dar cobertura a un asesoramiento médico en línea.

Ello plantea distintas cuestiones en la relación médico-paciente. Una relación que se basaba en la confianza y, sobre todo, en la presencialidad. No hay que olvidar que el paciente encuentra en la atención del médico no solo la curación, sino también el sosiego y la confianza en una persona. Si ello se sustituye por un robot, esa relación médico-paciente cambia, pues el primero adquiere ya una connotación diferente no solo en el ámbito humano, sino también en el jurídico. La automatización de la praxis médica revierte en una máquina el deber de cuidado del paciente (Perin, 2019: 10).

Nos proponemos en el presente trabajo, en una primera parte, analizar las implicaciones que tiene o puede tener la inteligencia artificial en el entorno de la relación médico-paciente a través del tratamiento de distintas cuestiones relacionadas, como es el caso de la autonomía de la voluntad, la personalidad jurídica de los robots, la responsabilidad civil por daños causados por autómatas y la protección de datos en las aplicaciones de diagnóstico mediante inteligencia artificial; en una segunda parte, entregaremos algunas propuestas de lege ferenda sobre una normativa específica de inteligencia artificial basada en la robótica médica en los aspectos referentes a la relación médico-paciente. Concluiremos el trabajo con unas breves reflexiones sobre los puntos analizados con aportes de interés para la comunidad científica. 


\section{De los macrodatos, big data, robots e inteligencia artificial: Algunas precisiones previas}

Cuando nos referimos a las nuevas tecnologías, nos encontramos con algunos conceptos que no son fáciles de entender, como macrodato, robot e inteligencia artificial. Vamos a intentar dar un concepto de cada uno de ellos.

Así, una definición de macrodato la encontramos en la Resolución del Parlamento Europeo, del 14 de marzo de 2017, sobre las implicaciones de los macrodatos en los derechos fundamentales: privacidad, protección de datos, no discriminación, seguridad y aplicación de la ley (2016/2.225 INI), que se refiere al concepto de macrodatos como recopilación, análisis y acumulación constante de grandes cantidades de datos, incluidos los datos personales, que procedan de distintas fuentes y objeto de tratamiento automatizado mediante algoritmos informáticos y avanzadas técnicas de tratamiento, utilizando datos almacenados y transmitidos en flujo continuo, con el objetivo de generar correlaciones, tendencias y patrones. La finalidad de los datos masivos es la determinación de los patrones de comportamiento (Suárez Gonzalo, 2017: 284).

Pero ¿qué es la inteligencia artificial? ¿La define alguna norma? Lo primero que debemos tener en cuenta es la definición que establece el Diccionario de la lengua española sobre este concepto: define la inteligencia artificial como la «disciplina científica que se ocupa de crear programas informáticos que ejecutan operaciones comparables a las que realiza la mente humana, como el aprendizaje o el razonamiento lógico». Su funcionamiento se basa (Martínez Devia, 2019: 8) en el desarrollo de sistemas computacionales (computing power) con la finalidad de procesar datos y llevar a cabo operaciones en tiempo reducido y con ampliación de la memoria de almacenamiento, y en los macrodatos o big data, que consisten en un volumen ingente de datos que se generan a través de diversas fuentes, como las propias máquinas, las biométricas y redes, precisan de inteligencia artificial para su gestión y se procesan para la obtención de resultados.

La implementación de la inteligencia artificial abre un abanico de posibilidades muy diverso, en el que no se puede dejar de lado el cumplimiento de los derechos fundamentales ${ }^{1}$ de los sujetos (Castellanos Claramunt y Montero Caro, 2020: 72), como es el derecho a la vida.

En la Resolución del Parlamento Europeo del 20 de octubre de 2020, con recomendaciones destinadas a la Comisión sobre un marco de los aspectos éticos de la inteligencia artificial, la robótica y las tecnologías conexas (2020/2012 INL), se indica la propuesta de un «Reglamento sobre principios éticos para el desarrollo, el des-

1. Teniendo en cuenta lo indicado respecto a estos derechos en la Constitución española, en su título 1, «De los derechos y deberes fundamentales». 
pliegue y el uso de la inteligencia artificial, la robótica y las tecnologías conexas». El objeto principal de este Reglamento es establecer un marco regulador dentro de la Unión Europea con visión de futuro de los principios éticos y obligaciones jurídicas para desarrollar, desplegar y utilizar tanto la inteligencia artificial como la robótica y demás tecnologías conexas. Incluye los programas informáticos, los algoritmos y los datos que se utilicen o produzcan por parte de dichas tecnologías, siempre que hayan sido desarrolladas, desplegadas o utilizadas en el seno comunitario. ${ }^{2}$

El Reglamento se refiere a la inteligencia artificial como un sistema que se basa en programas informáticos o se incorpora a dispositivos físicos que tiene un comportamiento inteligente, ya que puede ejecutar actividades como recopilar, analizar datos, interpretar el entorno y decidir con cierta autonomía para conseguir objetivos concretos.

En este sentido, cabe destacar que esta propuesta de Reglamento ya es una realidad, tras publicarse el 21 de abril de 2021 el documento «Proposal for a regulation on the European Parliament and of the council laying down harmonised rules on artificial intelligence (artificial intelligence act) and amending certain Union Legislative acts».

Como señalan Ávila, Mayer y Quesada (2021: 81), la inteligencia artificial está formada «por una serie de algoritmos lógicos suficientemente entrenados a partir de los cuales las máquinas son capaces de tomar decisiones para casos concretos a partir de normas generales». Se entiende por algoritmo, siguiendo la definición del Diccionario de la lengua española, un conjunto ordenado y finito de operaciones que tiene como finalidad encontrar la solución de un problema.

Otro concepto que nos interesa conocer es robot. Tirado Robles (2020: 43) -refiriéndose a la Resolución del Parlamento Europeo del 16 de febrero de 2017, que establece una serie de recomendaciones destinadas a la Comisión sobre normas de derecho civil sobre robótica, que aboga por «crear una definición generalmente aceptada de robot y de inteligencia artificial que sea flexible y no lastre la innovación»precisa algunas de las características que debe disponer un «robot inteligente», entre las que estarían ser capaz de adquirir autonomía mediante la utilización de sensores o el intercambio de datos, la capacidad de autoaprendizaje mediante experiencia e interacción, el disponer de un soporte físico y una capacidad de adaptación del comportamiento y actuaciones al entorno, así como no ser un ente con vida en un sentido puramente biológico.

Estos conceptos básicos nos facilitarán la comprensión de las cuestiones y los aspectos que vamos a exponer a lo largo del trabajo en relación con la medicina y la vinculación con los pacientes en un entorno digital.

2. Alberto J. Tapia Hermida, «Decálogo de la inteligencia artificial ética y responsable en la Unión Europea», Diario La Ley, 4 de diciembre de 2020, disponible en bit.ly/3zttmwK. 


\section{La inteligencia artificial y la medicina: ¿Médicos robots o robots médicos?}

La aplicación de la inteligencia artificial en ámbitos como la medicina supone un reto respecto a sus posibles consecuencias en el campo jurídico (Ruiz Hontangas, 2020: 47). Los avances tecnológicos que suponen una mayor precisión en el diagnóstico, un cálculo más aproximado de factores relevantes del paciente, así como la utilización de algoritmos que pueden predecir una probabilidad o recaída en el padecimiento de una enfermedad, plantean un escenario que es preciso regular. Nos encontramos, por tanto, ante un nuevo paradigma digital, en el que interviene la revolución $5 \mathrm{G}$ y la tecnología móvil (Lope Salvador, Mamaqi y Vidal Bordes, 2020: 68), y que en un futuro próximo puede producir una obsolescencia humana, ya que la previsión es un incremento de la automatización (Beltrán de Heredia Ruiz, 2020: 113).

En el ámbito médico se puede utilizar tanto la inteligencia artificial como la robótica. En este sentido, la inteligencia artificial se utiliza en el diagnóstico, seguimiento de patologías y en cuidados paliativos de los pacientes. También se aplica en la redistribución de recursos humanos y materiales, con la finalidad de dotar a los pacientes de una mayor atención, según su sintomatología (Cotino Hueso, 2020: 4).

Sin embargo, la relación entre la inteligencia artificial y la robótica es la participación del robot para ejecutar intervenciones quirúrgicas. El robot puede programarse con dicha finalidad y llevar a cabo operaciones a un paciente, bien de forma autónoma, o bien guiado por un especialista.

En el ámbito jurídico, por parte del Parlamento Europeo, se formulan una serie de recomendaciones respecto a los «robots médicos». Se especifica que se refiere a los «robots quirúrgicos» utilizados en cirugías de alta precisión. Ejemplos de este tipo de robots son los utilizados para cateterismo cardiaco, los cuales disponen de un sensor dotado de inteligencia artificial, y que, a través de un algoritmo, logran localizar en la válvula cardiaca la fisura u obstrucción de las arterias, en su caso (Loncaric y otros, 2021). También los que se usan para cirugía laparoscópica, con una mínima incisión y una más rápida recuperación del paciente. Desde el robot Arthrobot, de 1983, y el PUMA 560, de 1985, hasta el conocido Da Vinci (León Rodríguez, 2017: 105), son variadas las intervenciones asistidas por estas máquinas que proporcionan imágenes mucho más nítidas, en tres dimensiones, control de los movimientos involuntarios de la mano humana, suturas más completas y mejor acceso a cavidades del cuerpo en cirugías abiertas o laparoscópicas que resultan menos dificultosas, junto con una mejor funcionalidad posoperatoria en determinadas patologías (Balandrón, Gómez de Diego y Amat Santos, 2021: 82).

Se centra la Resolución del Parlamento Europeo, del 14 de marzo de 2017, en los requisitos para la utilización por parte de los facultativos de los «robots médicos» $\mathrm{y}$ que se «respete el principio de autonomía supervisada de los robots» estableciendo 
que «la elección final sobre la ejecución pertenece en todo caso al ámbito de decisión de un cirujano humano», como indica la citada Resolución. También menciona León Rodríguez (2017: 105) la utilización de robots en hospitales. Por ejemplo, el robot Gower para tareas de suministro, mezcla y dispensa de medicamentos y fármacos; en este último caso, con el fin de minimizar el error humano, se utiliza el robot en el cálculo de las dosis de medicamentos para la quimioterapia. Otro uso de los robots es el control del paciente y la entrega de medicamentos, lo que facilita la labor del personal de enfermería, ya que dispone de autonomía y precisión en las tareas encomendadas.

Incluso se utilizan en las unidades de cuidados intensivos (UCI) robots que disponen de monitores de ordenador y se desplazan para la atención de los pacientes que requieren un seguimiento permanente, con control remoto por parte de médicos, de forma que se les permite seguir el estado de varios pacientes de forma simultánea (León Rodríguez, 2017: 105). Se extiende también el uso de los dispositivos de control mediante un robot para eliminar la distancia física entre paciente y médico, en el caso de problemas de cobertura médica, utilizando cámaras para establecer comunicación con el paciente (León Rodríguez, 2017: 105).

Se utilizan también robots dispensadores de fármacos, como el caso de IntelliFill I. V., con capacidad de llenado de jeringuillas, con lo que se robotiza la dispensa de medicación, se evita el exceso de recursos humanos y se obtiene eficacia en la atención de los pacientes.

Cuestión distinta es la utilización de la inteligencia artificial como herramienta para el autodiagnóstico, a través de robots móviles, y apuntan las normas de Derecho civil sobre robótica que la Resolución del Parlamento Europeo, del 16 de febrero de 2017, formula que «estas tecnologías no deberían disminuir ni perjudicar la relación entre médico y paciente, sino proporcionar al médico una asistencia para el diagnóstico y/o el tratamiento de los pacientes, con el fin de reducir el riesgo de error humano y aumentar la calidad y la esperanza de vida».

Otro aspecto que se trata en las recomendaciones destinadas a la Comisión sobre normas de Derecho civil sobre robótica de la Resolución del Parlamento Europeo, del 16 de febrero de 2017, a las que estamos haciendo referencia es el de las intervenciones en el cuerpo humano, mediante la rehabilitación de órganos dañados y el restablecimiento de funciones del cuerpo que se han visto afectadas por enfermedades o accidentes. Ello precisa que los comités de ética de los centros y hospitales se pronuncien sobre la implantación de dispositivos en el ser humano. Por ejemplo, un caso reciente lo tenemos con una persona que se injertó una antena en la cabeza, dado que sufría de monocromatismo, para poder "oír los colores», con lo que se convirtió en lo que se ha denominado un ciborg. ${ }^{3}$ También el caso de

3. Bruno Martín, «Los extraordinarios cambios de personalidad causados por implantes cerebrales», Open Mind BBVA, 30 de octubre de 2019, disponible en bit.ly/3xjmhNo. 
un sujeto que se implantó unas aletas artificiales en el cráneo para «sentir las vibraciones atmosféricas». ${ }^{4}$

Se deben establecer parámetros sobre la conveniencia o no de utilizar el cuerpo humano como campo de experimentación en el ámbito de la inteligencia artificial, y diseñar un protocolo adecuado para la implantación de dispositivos que no tengan como finalidad una mejora médica o ayuda a una patología. Ello abre el debate de las «prótesis robóticas» y su mantenimiento a través de un software que garantice las actualizaciones necesarias (Sánchez Navarro, 2018: 257).

También la inteligencia artificial tiene su desarrollo en el caso de aplicaciones de móviles o aplicaciones informáticas derivadas de las TIC, de lo que se plantea la cuestión de la protección de datos personales en el ámbito de la salud. ${ }^{5}$ En un escenario virtual a través de programas de diagnóstico, los datos masivos o big data (Ramón Fernández, 2020b) cuestionan distintos conflictos en relación con su utilización (Ramón Fernández, 2018), así como los datos de personas que ya han fallecido (Ramón Fernández, 2020a).

A su vez, la doctrina se ha referido a la inteligencia artificial aplicada a la medicina a través de lo que se ha denominado redes neuronales artificiales (Del Río Solá, López Santos y Vaquero Puerta, 2018: 115), que son modelos informáticos que simulan el funcionamiento cerebral y que pueden ser aplicados a ámbitos como el diagnóstico y detección del cáncer y patologías cardiacas; analíticas para la detección de alteraciones bioquímicas; imágenes a través de su procesamiento misma mediante instrumentos de alta definición; y farmacología, así como modelado de biomoléculas. Se utilizan algoritmos de retropropagación. ${ }^{6}$

También se utilizan estas aplicaciones basadas en la inteligencia artificial como apoyo logístico a la práctica médica (Del Río Solá, López Santos y Vaquero Puerta, 2018: 115), tanto en la asistencia en el procesamiento de las imágenes como en el manejo de pacientes de alto riesgo, y para evaluar y determinar el diagnóstico de enfermedades cardiacas, principalmente el caso de infarto agudo de miocardio y cardiopatías congénitas.

4. María Usán, «Los cíborgs, personas con "órganos” tecnológicos: "Siento que me faltan unas aletas en la cabeza"», Heraldo, 29 de diciembre de 2019, disponible en bit.ly/3gCtykA.

5. Se entiende por dato personal -según el artículo 4 del Reglamento (UE) 2016/679 del Parlamento Europeo y del Consejo de 27 del abril de 2016, relativo a la protección de las personas físicas en lo que respecta al tratamiento de datos personales y a la libre circulación de estos datos y por el que se deroga la Directiva 95/46/CE - «toda información sobre una persona física identificada o identificable ("el interesado"); se considerará persona física identificable toda persona cuya identidad pueda determinarse, directa o indirectamente, en particular mediante un identificador, como por ejemplo un nombre, un número de identificación, datos de localización, un identificador en línea o uno o varios elementos propios de la identidad física, fisiológica, genética, síquica, económica, cultural o social de dicha persona».

6. Se refiere a algoritmos que se utilizan para mejorar los resultados de una máquina, y se aplica en el caso de redes neuronales artificiales. 


\section{Robots como instrumentos de ayuda a ancianos, discapacitados y dependientes: Más allá de la medicina}

Las funciones de la robótica en el ámbito médico también podían completarse con otras actividades que podrían ser muy beneficiosas, como es el caso que indica Aceros Gualdrón (2018: 57) al referirse a la ayuda que pueden proporcionar los robots a los ancianos en situación de deterioro cognitivo o dependientes, para recordarles la toma de medicamento o entrega de medicinas.

La robótica también se aplica tanto en el cuidado de la tercera edad, lo que se conoce como geronrobótica (Aceros Gualdrón, 2018: 48), como para la atención a personas discapacitadas y dependientes, ya que suponen una ayuda en las tareas cotidianas, entre las que se encuentra el aseo, vestido o alimentación, así como en la ayuda para ejecutar distintos desplazamientos. También se utiliza la robótica para la administración de medicamentos, control de las constantes vitales y el análisis de datos relativos a las pruebas médicas al paciente.

En este sentido, destaca la aplicación de la robótica para la integración social de las personas que sufren una disfunción motora o algún grado de discapacidad. No hay que olvidar la importancia del factor de humano, ya que aunque los robots puedan «ayudar» en tareas de vigilancia y cuidado, los cuidadores humanos no van a poder ser sustituidos, ya que ofrecen una interacción persona a persona, lo que hoy un robot no puede reemplazar.

\section{La inteligencia artificial y su aplicación en la relación médico-paciente: Algunas cuestiones}

La relación en medicina entre el médico y el paciente siempre ha sido de carácter presencial, en el que los sujetos acudían al facultativo en busca de alivio o curación, y deseaban ser atendidos por un buen profesional al que le avalaran conocimientos adquiridos con esfuerzo y dedicación. Sin embargo, estas aptitudes y capacidades van progresivamente siendo adquiridas por dispositivos tecnológicos. Además, los propios especialistas también disponen de información y tecnología muy superior a la del siglo pasado. Por ello, la relación entre las personas en el ámbito de la medicina ha cambiado, junto con la forma de relacionarse (Chivato Pérez, 2019: 121), en el que la tecnología más puntera se abre camino de un modelo asistencial basado en el paternalismo a un modelo en el que el paciente es mucho más activo y dispone de herramientas desarrolladas por la tecnología para el tratamiento de su patología. Esto necesariamente supone un cambio de paradigma en el trato, que puede derivar en una mayor deshumanización en favor de una tecnología más precisa, pero también se trata de orientar dicha situación a la humanización de la tecnología, haciéndola más cercana y sensible a su destinatario. 
Esa relación médico-paciente podría cambiar por otros aspectos, como la «fe» del paciente en el robot más que en el humano, o el efecto placebo que podría producir el robot.7

Cuando se habla de la relación entre médico y paciente en el derecho español, resulta de interés mencionar la Ley 41/2002, del 14 de noviembre, básica reguladora de la autonomía del paciente y de derechos y obligaciones en materia de información y documentación clínica. Esta norma de ámbito estatal pone su punto de mira en los derechos de los pacientes. Parte de la Declaración Universal de los Derechos Humanos de 1948, en el artículo 25 establece el derecho a recibir asistencia médica, en el que queda implícita una relación con el facultativo que va a prestar la asistencia; y la Declaración de la Organización Mundial de la Salud para la promoción de los derechos de los pacientes en Europa, de 1994, la que reconoce el «derecho a elegir y cambiar de médico», muestra del establecimiento de una relación entre ambos, que puede quebrarse por determinadas circunstancias.

Por su parte, el Convenio para la protección de los Derechos Humanos y la dignidad del ser humano con respecto a las aplicaciones de la biología y la medicina, de 1997 (conocido como Convenio de Oviedo), reconoce una serie de derechos, como los de información y dignidad, que se plasmarán en la posterior legislación.

En la mencionada Ley 41/2002 se indican algunas pautas de la relación entre el médico y el paciente, como:

- Facilitar el médico de forma previa información referente a los actos y tratamientos médicos, para que el paciente, si está de acuerdo, preste su consentimiento de forma expresa y por escrito. Es el denominado «consentimiento informado».

- El paciente dispone de autonomía y libertad de decidir si recibe el tratamiento o negarse a él.

- El paciente debe facilitar datos e información sobre su situación y estado físico de forma leal y verdadera, y mostrar su colaboración en los casos de interés público o de recibir asistencia sanitaria.

- El médico o personal sanitario está obligado a prestar de forma correcta las técnicas, a cumplir los deberes de información y documentación clínica, y a respetar las decisiones adoptadas por el paciente.

La Ley define, además, los conceptos de médico responsable y de paciente. Se considera al primero como el profesional que coordina la información y asistencia sanitaria del paciente, junto con ser el interlocutor principal respecto a la atención e

7. Luis Menéndez, «Vídeos “deepfakes”: La desinformación tiene un nuevo formato», Escritura Pública, julio-agosto de 2019, disponible en bit.ly/3vm3sYB. 
información, si bien pueden intervenir otros sujetos en su atención. Por su parte, el segundo es el sujeto que precisa asistencia sanitaria y se somete a los cuidados profesionales para mantener o recuperar la salud (artículo 3 de la Ley 41/2002).

Como vemos, no se precisa ni se hace referencia a una asistencia médica de tipo virtual, ni tampoco a que el médico sea un robot o pueda ser establecida una relación entre un paciente y una máquina. La Declaración de Lisboa de la Asociación Médica Mundial sobre los derechos del paciente, de 1981, incide en la figura del médico como persona física, al establecer como uno de los principios el «derecho a la atención médica de buena calidad», lo cual incluye que «todo paciente tiene derecho a ser atendido por un médico que él sepa que tiene libertad para dar una opinión clínica y ética, sin ninguna interferencia exterior».

Todas estas indicaciones decaen en el caso de que se mencione la inteligencia artificial y su aplicación en la relación médico-paciente. Podemos referirnos a su utilización como apoyo al médico persona física, o bien a su utilización para el desarrollo de máquinas o robots capaces de cumplir la actividad de un médico persona física. En ambos casos, la relación entre médico robot y paciente va a ser muy distinta, y desde luego debe ser encuadrada dentro de una legislación aplicable, de la cual todavía no disponemos.

La inteligencia artificial y su aplicación en el caso de la denominada «atención primaria» - lo que se conoce como «médico de cabecera»- puede ser muy útil para agilizar las listas de espera de los centros de salud, y poder realizar una asistencia más amplia no solo en situaciones habituales, sino también en los casos de crisis sanitarias, como en la actualidad por el covid-19.

Esta afirmación ya ha sido puesta de relieve por Cotino Hueso (2020:4) al hacer referencia a la situación de crisis sanitaria, y con mención de la Comunicación de la Comisión de la Unión Europea (2020/C 124 I/o1), referente a las orientaciones sobre las aplicaciones móviles de apoyo a la lucha contra la pandemia de covid-19, en el que se menciona la telemedicina como una de las funcionalidades del tratamiento de datos a través de las llamadas y el seguimiento o rastreo de los contactos.

También destaca su utilización en el ámbito de envío de mensajes personalizados a los pacientes atendiendo a su particular perfil (Cotino Hueso, 2020: 4). Las nuevas tecnologías aplicadas al ámbito médico formarían parte de una medicina más personalizada y diseñada según las necesidades del paciente (Ávila de Tomás, Mayer Pujadas y Quesada Varela, 2021: 82). Potenciarían también una mayor trazabilidad y eficacia en la gestión de los centros de salud y hospitales, ya que se dispondría de una información en tiempo real de número de pacientes y patologías asociadas.

Hemos mencionado algunos aspectos de la relación médico-paciente, cuando ambos son personas físicas, como el derecho de información, respeto a la autonomía de la voluntad y dignidad, entre otros. Se plantearía en el ámbito jurídico por parte de la doctrina cómo se ejercerían estos derechos en el caso de que el médico sea un robot 
(Rogel Vide, 2018: 79). Se tendría que hacer mención a lo que se ha denominado por la doctrina como personalidad jurídica electrónica (Lacruz Mantecón, 2019: 85; Rojo Gallego-Burín, 2020: 10). El Parlamento Europeo, en la citada Resolución del 16 de febrero de 2017, hace mención a la necesidad de que la inteligencia artificial «preserve la dignidad, la autonomía y la autodeterminación del individuo, especialmente en el ámbito de la atención y la compañía a las personas, y en el contexto de los dispositivos médicos que "reparen" o mejoren a los seres humanos".

La Resolución menciona también el contacto humano, lo que hemos indicado respecto de la relación médico-paciente, un elemento que es necesario tener en cuenta, puesto que la eliminación de ese factor humano por robots podría conllevar la deshumanización de los cuidados. No obstante, también muestra la otra vertiente, es decir, la posibilidad de que los robots realicen actividades destinadas a proporcionar cuidados a las personas, descargando al personal médico de dichas tareas, para dedicarse de forma más intensiva al diagnóstico y a la planificación.

Una de las últimas recomendaciones del Parlamento Europeo es la creación de «entidades de confianza independientes». Su finalidad es proporcionar soporte técnico y asistencial a las personas que utilicen «dispositivos médicos vitales», como marcapasos, cuando se necesiten piezas de recambio y no se dispongan de las originales, por lo que se recomienda se proporcionen «instrucciones de diseño global, incluido el código fuente, a estas entidades de confianza independientes, de forma similar al depósito legal de publicaciones en una biblioteca nacional».

Otro punto para tener en cuenta es lo que la doctrina denomina «decisiones automatizadas» sin la intervención humana (Castellanos Claramunt, 2020: 69), en la que se podría plantear tratamiento de los datos personales para evaluar aspectos de la persona, en este caso, relacionados con la salud. Debe ser informado el paciente al respecto y contemplarse el derecho a obtener una intervención humana, a que el interesado pueda tener derecho de audiencia, y recibir una explicación de la decisión adoptada y la posibilidad de impugnarla. Ello entroncaría con la necesidad de establecer políticas de transparencia en los algoritmos que se utilizan para la adopción de decisiones por parte de las máquinas, de conformidad con lo indicado en la actual Ley 19/2013, del 9 de diciembre, de transparencia, acceso a la información pública y buen gobierno.

\section{La relación robot-paciente y su responsabilidad civil en el ámbito médico: ¿Son responsables los robots?}

Cuando nos referimos a la responsabilidad civil en el ámbito médico, debemos distinguir dos ámbitos diferentes:

- La responsabilidad por una mala actuación del robot, que puede causar un daño físico al paciente, en los casos en que el robot lleve a cabo una intervención quirúrgica. 
- La responsabilidad que se produce cuando el robot proporciona un diagnóstico erróneo, que determina un daño al paciente en cuanto a la patología que padece (Ramón Fernández, 2019: 4).

Respecto a la imputación de la responsabilidad, hay que atender a la legislación comunitaria, ya que la legislación española no contiene disposiciones en materia de robótica.

En este sentido, podemos mencionar el «Libro blanco sobre la inteligencia artificial: Un enfoque europeo orientado a la excelencia y la confianza», ${ }^{8}$ que se hace eco sobre la peculiaridad de los sistemas de inteligencia artificial en el ámbito de la información médica, indicando al respecto:

Las consideraciones de seguridad y las implicaciones jurídicas son distintas en el caso de los sistemas de inteligencia artificial que ofrecen información médica especializada a los médicos, los sistemas de inteligencia artificial que ofrecen información médica al paciente y los sistemas de inteligencia artificial que ofrecen por sí solos prestaciones médicas al paciente directamente. La Comisión está examinando estos retos de seguridad y responsabilidad civil, que son distintos de la asistencia sanitaria.

Debemos tener en cuenta, además, lo establecido en la Resolución del Parlamento Europeo, del 20 de octubre de 2020, con recomendaciones destinadas a la Comisión sobre un régimen de responsabilidad civil en materia de inteligencia artificial (2020/2014 INL) (Anguita Ríos, 2020; Atienza Navarro, 2020; Da Silveira, 2020; Fossaseca y Moreyra, 2020: 25), ya que nos proporciona unas pautas adecuadas sobre la responsabilidad, en la que se refiere también a las actuaciones derivadas de la robótica.

Cuando hablamos de responsabilidad civil, nos referimos a los daños causados por culpa o negligencia. Se distingue la responsabilidad de tipo objetivo o sin culpa y la subjetiva o por culpa, cuya existencia debe ser probada. La evolución del concepto de culpa en el ordenamiento jurídico español ha sido observada a través de la jurisprudencia, en la que el criterio pasó de un concepto subjetivo en la responsabilidad extracontractual a uno objetivo, dado que la prueba de la culpa en el primer caso a veces se convertía en lo que se denominó probatio diabolica. ${ }^{9}$

La responsabilidad civil por daños constituye una garantía para que el sujeto pueda reclamar una indemnización, y actúa también como elemento disuasorio ante posibles comportamientos dañinos por parte de los sujetos. En el caso que nos ocupa, la responsabilidad, como hemos indicado, puede generarse bien porque la máquina

8. «Libro blanco sobre la inteligencia artificial: Un enfoque europeo orientado a la excelencia y la confian$z a »$, Comisión Europea, 19 de febrero de 2020, $\operatorname{COM(2020)} 65$ final, p. 21, disponible en bit.ly/3wugvsh.

9. Sentencia del Tribunal Supremo, rol 1.768/2014, 9 de mayo de 2014, ECLI: ES:TS:2014:1768. 
produzca un daño por cualquier motivo; no puede olvidarse que puede tratarse de un producto defectuoso, en cuyo caso habrá que atender a lo indicado en la Directiva 85/374/CEE del Consejo, del 25 de julio de 1985, relativa a la aproximación de las disposiciones legales, reglamentarias y administrativas de los Estados miembros en materia de responsabilidad por los daños causados por productos defectuosos, y la Directiva 98/27/CE del Parlamento Europeo y del Consejo, del 19 de mayo de 1998, relativa a las acciones de cesación en materia de protección de los intereses de los consumidores, y que quedaron ya incorporadas al ordenamiento jurídico español en el Real Decreto Legislativo 1/2007, del 16 de noviembre, por el que se aprueba el texto refundido de la ley general para la defensa de los consumidores y usuarios y otras leyes complementarias. Se contempla una responsabilidad de tipo solidario, por indicación específica de la norma.

Aunque la legislación española no menciona ni a los robots ni a las máquinas, consideramos que por aplicación del artículo 136 del Real Decreto Legislativo 1/2007, en el que se considera como producto «cualquier bien mueble, aun cuando esté unido o incorporado a otro bien mueble o inmueble, así como el gas y la electricidad», se podría extrapolar este concepto al ámbito de los robots.

Se considera como producto defectuoso a aquel que no ofrece la seguridad esperada, y, como indica el artículo 137 del Real Decreto Legislativo 1/2007, «teniendo en cuenta todas las circunstancias y, especialmente, su presentación, el uso razonablemente previsible del mismo y el momento de su puesta en circulación». Se tiene en cuenta la seguridad media ofrecida por el resto de los productos de la misma serie, por lo que habrá que atender al funcionamiento y la seguridad ofrecida en el caso de los robots quirúrgicos.

La responsabilidad civil por daños comprende los datos personales (daños en el cuerpo, incluido el fallecimiento) y daños materiales (daños provocados por el robot en las instalaciones en que se haya utilizado). La responsabilidad en estos casos recae sobre el productor, que responderá de los defectos de los productos que haya fabricado o importado. El Real Decreto Legislativo 1/2007 nos indica, en su artículo 138, que se considera como productor al fabricante o importador en la Unión Europea de un producto ya terminado, sus elementos o una materia prima. Se remite el precepto al artículo 5 del mismo texto legal, respecto al concepto de productor, en el que incluye «al prestador del servicio o su intermediario, o al importador», y también «cualquier persona que se presente como tal al indicar en el bien, ya sea en el envase, el envoltorio o cualquier otro elemento de protección o presentación, o servicio su nombre, marca u otro signo distintivo».

Las causas por las cuales el productor no será responsable se indican en el artículo 140 del Real Decreto Legislativo 1/2007: cuando no haya puesto en circulación el producto; se presuma que el defecto no existía cuando se puso en circulación el bien; que el producto no se fabricó para su puesta en venta; que el defecto ha sido causado por 
su elaboración conforme a «normas imperativas existentes», o bien que el estado de la ciencia cuando se distribuyó el producto no permitió apreciar la existencia del defecto. Aquí nos planteamos la posibilidad de aplicar la doctrina de los vicios ocultos.

También se contempla como exoneración de responsabilidad el caso que indica el artículo 140.2 del Real Decreto Legislativo 1/2007, cuando «el productor de una parte integrante de un producto terminado no será responsable si prueba que el defecto es imputable a la concepción del producto al que ha sido incorporado o a las instrucciones dadas por el fabricante de ese producto».

En cuanto a la infalibilidad de los robots para proporcionar un diagnóstico, consideramos que evidentemente no son infalibles y que «pueden equivocarse». Aquí se darían dos supuestos diferentes: el diagnóstico erróneo proporcionado por el robot ante una prueba médica de fluidos o imagen; y el diagnóstico erróneo cuando el facultativo interpreta de forma errónea los resultados. En este último caso, la responsabilidad derivaría en el facultativo, no en el robot. Pero en el primer caso, la depuración de responsabilidad devengaría en el robot y consideramos que según lo mencionado en la anterior Resolución del Parlamento Europeo, del 20 de octubre de 2020.

\section{Necesidad de una legislación específica de inteligencia artificial aplicada a la robótica médica}

La ausencia de una legislación no solo a nivel comunitario, sino también a nivel estatal español de la inteligencia artificial y su aplicación al ámbito de la medicina, plantea diversas cuestiones y conflictos en orden a su resolución.

No se dispone de normativa específica que determine los aspectos éticos o jurídicos en relación con la robótica médica, no ya solo en el ámbito de la responsabilidad civil, sino también en las relaciones con los pacientes. La deshumanización de la medicina a través de la robótica no debe establecerse como un vacío legal, sino que precisamente, por tratarse de un nuevo escenario con el que nos podemos encontrar, debe ser regulado en el ámbito de los derechos y las obligaciones.

Esta legislación debe apostar por evitar malos usos de la inteligencia artificial y de los algoritmos, junto con la infracción de los derechos fundamentales del ser humano. Debe ser concebida a nivel comunitario disponiendo de lo que se ha denominado «un marco jurídico horizontal y armonizado basado en principios comunes», como ha señalado la Resolución del Parlamento Europeo del 20 de octubre de 2020.

Sobre los mimbres que disponemos en la actualidad aplicables a la responsabilidad civil, a los que hemos hecho referencia en el punto anterior, deben añadirse aspectos regulatorios complementarios en relación con la autonomía de los dispositivos en que está presente la inteligencia artificial, como los robots, para evitar situaciones en las que se produzca un daño y se tenga que indemnizar al sujeto. No hay que olvidar que la indicada personalidad electrónica es la que va a permitir la 
imputación de la máquina a través de su responsable, como ha tenido oportunidad de señalar la Resolución del Parlamento Europeo, del 16 de febrero de 2017, al indicar «de forma que como mínimo los robots autónomos más complejos puedan ser considerados personas electrónicas responsables de reparar los daños que puedan causar, y posiblemente aplicar la personalidad electrónica a aquellos supuestos en los que los robots tomen decisiones autónomas inteligentes o interactúen con terceros de forma independiente».

Por su parte, la Carta Abierta a la Comisión Europea referente a la inteligencia artificial y robótica indicó la preocupación por que la Comisión Europea indicara la creación de una personalidad jurídica para los robots. ${ }^{10}$ Consideran que es inapropiado, sea cual sea el modelo de estatus legal que se adopte. Por tanto, no consideran un estatus legal derivado del modelo de persona natural, ya que sería atribuir derechos humanos al robot, como el derecho a la dignidad, integridad o ciudadanía, e iría en contra de lo indicado en la Carta de los Derechos Fundamentales de la Unión Europea y el Convenio para la Protección de los Derechos Humanos y las Libertades Fundamentales.

Tampoco resultaría oportuno dotar al robot de un estatus derivado de un modelo de entidad jurídica, ya que implicaría la existencia de seres humanos detrás de la persona jurídica como representantes y directores. Y mucho menos a través del modelo anglosajón de fiducie, o treuhand en Alemania, por no solventar el problema de responsabilidad (Bueno Ochoa, 2020: 49).

En otras ocasiones es el sujeto el que programa al robot, por lo que se aplicaría el régimen actual de responsabilidad civil, pero sería preciso establecer un sistema adecuado para la trazabilidad en las intervenciones del sujeto en relación con la máquina, ya que la Directiva aplicable e indicada anteriormente no resultaría del todo suficiente para la tecnología digital, ya que debería adaptarse al entorno digital con la finalidad de proteger los intereses de los consumidores y usuarios. Por ende, esta modificación debería después incorporarse a los ordenamientos jurídicos respectivos teniendo en cuenta las peculiaridades del ámbito de aplicación.

Como indicó en su momento Ebers (2016: 21), la ventaja de atribuir responsabilidad propia del robot es que se superarían mejor las cuestiones de responsabilidad. «El agente podría, como sujeto responsable independiente, ser interpelado, $y$, pensando en esta eventualidad, ser dotado con un patrimonio, para, antes incluso de ser objeto de una utilización proclive al riesgo, disponer en el tráfico jurídico de un suficiente fondo de responsabilidad».

Se tendría que definir de forma clara y precisa qué se considera como producto digital o robot, y ello iría en consonancia con lo que define la propuesta de «Regla-

10. «Open letter to the European Commission artificial intelligence and robotics», Robotics Openletter, disponible en bit.ly/3wviKLJ. 
mento sobre principios éticos para el desarrollo, el despliegue y el uso de la inteligencia artificial, la robótica y las tecnologías conexas» que establece la Resolución del Parlamento Europeo, del 20 de octubre de 2020, la cual define la robótica como «las tecnologías que permiten que las máquinas controladas automáticamente, reprogramables y multifuncionales realicen en el mundo físico acciones tradicionalmente realizadas o iniciadas por los seres humanos, en particular mediante la inteligencia artificial o las tecnologías conexas».

Es por ello que la futura legislación debe incluir como responsables en el ámbito de la responsabilidad civil no solo al productor o fabricante, como hace actualmente la legislación aplicable, sino también a quien desarrolla un software o programa el robot, e incluir los programas informáticos libres y de código abierto. En este sentido, apuesta por la diferenciación entre el defecto del diseño informático y los defectos de diseño e información (Navas Navarro, 2020: 43).

Hay que tener en cuenta que la actual normativa a la que hemos hecho referencia no indica que el bien a la hora de referirse a un producto sea un bien corporal, ya que no lo precisa de forma específica, por lo que también se podrían considerar incluidos los denominados bienes inmateriales, aludiendo a la propiedad intelectual (Navarro Michel, 2020: 181); también porque el tratamiento en la Directiva UE 2019/771 del Parlamento Europeo y del Consejo, del 20 de mayo de 2019, relativa a determinados aspectos de los contratos de compraventa de bienes, por la que se modifican el Reglamento CE 2017/2.394 y la Directiva 2009/22/CE y se deroga la Directiva 1999/44/CE, considera que dentro del concepto de bienes se debe entender incluido los denominados «bienes digitales», con lo que se refiere a «a cualquier contenido o servicio digital que se incorpore a dichos bienes o se interconecte con ellos». Estos contenidos digitales incorporados pueden ser sistemas operativos, aplicaciones o programas informáticos.

Como señala Navarro Michel (2020: 182), esta Directiva UE 2019/771 «permite afirmar que el software puede ser un producto a efectos de la responsabilidad por producto defectuoso». Ello también supondrá reconsiderar la actual Directiva 2001/95/ CE del Parlamento Europeo y del Consejo, del 3 de diciembre de 2001, relativa a la seguridad general de los productos, por cuanto no se menciona a los productos en los que interviene la inteligencia artificial, respecto a la incorporación de seguridad y protección.

En definitiva, los riesgos asociados a la inteligencia artificial en dispositivos aplicados a la práctica médica no se contemplan en la actual legislación y sería preciso o bien legislar específicamente sobre ello o, en su defecto, realizar las modificaciones necesarias en la actual normativa.

Otro de los aspectos en los que se debería centrar la legislación es en materia de protección de datos. Actualmente se aplica el Reglamento UE 2016/679, al que hemos hecho referencia, y que menciona la Directiva 2011/24/CE del Parlamento Europeo y del Consejo, del 9 de marzo de 2011, relativa a la aplicación de los derechos de los 
pacientes en la asistencia sanitaria transfronteriza. Esta directiva incluye dentro de los datos personales relativos a la salud los datos proporcionados por un dispositivo médico, entre los que se encontrarían los robots. Esta referencia a los dispositivos médicos no se incluye en la Ley Orgánica 3/2018, del 5 de diciembre, de protección de datos personales y garantía de los derechos digitales, ni tampoco hace mención a la robótica ni a la inteligencia artificial en la regulación del tratamiento de datos de salud en la disposición adicional decimoséptima.

La Agencia Española de Protección de Datos (2020: 52) estableció unas pautas referentes a los límites en la privacidad, para la adecuación al Reglamento General de Protección de Datos de los tratamientos que incorporan inteligencia artificial, indicando en materia de salud y sanidad los que se basaban en el análisis de imágenes.

Otro aspecto para tener en cuenta es si en el ámbito de la medicina se utilizarán hologramas para establecer la relación médico-paciente a través de inteligencia artificial. Con la posibilidad de mostrar imágenes utilizando láser (Pérez-Borges, 2011: 255). La realidad virtual y aumentada plantearía cuestiones jurídicas en relación con el derecho personalísimo de la imagen como un derecho fundamental reconocido en el artículo 18 de la Constitución española, y regulado en la Ley Orgánica 1/1982, del 5 de mayo, de protección civil del derecho al honor, a la intimidad personal y familiar $y$ a la propia imagen, $y$ en la que no se menciona tampoco la inteligencia artificial en la creación de imágenes y su protección.

También habría que mencionar los denominados deepfakes o imágenes creadas utilizando algoritmos (Chesney y Keats Citron, 2019: 85; Menéndez, 2019: 19; Robles Lessa, Boechat Cabral y Fachetti Silvestre, 2020: 477; Cerdán Martínez, García Guardia y Padilla Castillo, 2020: 165), con la simulación de un médico, en el que se podría producir una confusión o información falsa en la relación entre médico-paciente si el primero es un deepfake. Deberían contemplarse en una legislación los instrumentos y herramientas para detectar la verdad de lo falso, y establecer protocolos de actuación adecuados para salvaguardar los derechos de los pacientes.

\section{Conclusiones}

La aplicación de nuevas formas de diagnóstico y atención médica mediante la utilización de la inteligencia artificial, los algoritmos y las nuevas tecnologías de la información y comunicación necesitan adaptarse a la legislación existente, o bien que se legisle ex profeso sobre ello (Peguera Poch, 2020), lo que ha doctrina ha bautizado como lex robótica (García Mexía, 2016; Barrio Andrés, 2020).

A nivel comunitario europeo, son diversas las iniciativas que se han producido en los últimos años en torno a la robótica, la inteligencia artificial y su aplicación en el ámbito médico. Esa normativa de futuro debe ser aplicada de forma directa o bien transpuesta en el ordenamiento jurídico español. 
La relación médico-paciente en un entorno de inteligencia artificial y a través de la intervención de algoritmos cambia el entorno presencial como lo conocemos. Resulta fundamental la preservación de los derechos del paciente y sobre todo su autonomía de la voluntad. La aparición de aplicaciones o programas informáticos que puedan facilitar la consulta médica no debe eliminar ni alterar los protocolos actuales en materia de diagnóstico o de atención sanitaria. Se hace necesario elaborar pautas para evitar una indefensión y un posterior daño al sujeto, ya que otro de los aspectos clave de la intervención de la robótica en la medicina es la responsabilidad y los sujetos responsables, por lo que se aboga por una personalidad jurídica electrónica para evitar que queden sin indemnización hechos dañosos provocados por los robots. Sin embargo, como señala García Mexía (2020), la atribución de una personalidad electrónica a los robots no es una solución adecuada, ya que supone una erosión en el papel de la persona humana ante los supuestos de responsabilidad, ${ }^{11}$ por lo que la necesidad de contar con una legislación específica sobre la materia se hace muy necesaria (García Mexía, 2020). Por otra parte, Navas Navarro considera que se trataría de un supuesto de responsabilidad por hecho ajeno, con la finalidad de que se le pueda imputar la acción dañosa, pero sin significar que vaya a responder por ella. ${ }^{12}$

Consideramos también que es preciso delimitar la asunción de esa responsabilidad ampliando su ámbito subjetivo no solo al fabricante, sino también al programador o responsables del software.

Otro de los aspectos que hemos analizado es la vinculación de la inteligencia artificial con el big data. La minería de datos que se genera con los datos masivos y el empleo de los algoritmos plantea un reto entorno a la privacidad que la doctrina ya ha puesto de manifiesto (Castellanos Claramunt, 2020: 61). Es por ello por lo que la normativa también tiene que adaptarse a dicha circunstancia y tener en cuenta las aplicaciones de móviles y programas informáticos en el ámbito de la salud, la utilización de datos personales y el respeto a los derechos fundamentales. De especial interés resulta la mención del artículo 18.4 de la Constitución española, que establece que «la ley limitará el uso de la informática para garantizar el honor y la intimidad personal y familiar de los ciudadanos y el pleno ejercicio de sus derechos», y que ha sido refrendado por el Convenio Europeo de Derechos Humanos de 1950, en su artículo 8, así como por el Convenio para la protección de las personas con respecto al tratamiento automatizado de datos de carácter personal, de 1981, en su artículo 1, y la Carta de los Derechos Fundamentales de la Unión Europea, de 2016, en su artículo 8.

11. Carlos B. Fernández, «El reconocimiento de una personalidad jurídica electrónica no es adecuada para regular la responsabilidad por daños causados por sistemas inteligentes», Diario La Ley, 16 de diciembre de 2019, disponible en bit.ly/3wrIp88.

12. Susana Navas Navarro, «Sistemas expertos basados en inteligencia artificial y responsabilidad civil, Diario La Ley, 11 de diciembre de 2019, disponible en bit.ly/350QIWE. 
Es por todo ello que la inteligencia artificial debe ser limitada legislativamente en cuanto a la utilización y reutilización de los datos personales, con la finalidad de evitar riesgos para los titulares, teniendo en cuenta que estamos hablando de datos especialmente protegidos y sensibles, como son los datos de salud. En el ámbito de la inteligencia artificial resulta primordial la ética y su preservación (Guerris, 2020: 58), y por ello la adaptación de la normativa a la actual era digital se hace cada vez más acuciante (Martínez Devia, 2019: 7).

A pesar de todo lo ya indicado, no hay que considerar que se debe contemplar el escenario que nos podemos encontrar como negativo - la doctrina incluso se plantea si la situación va a suponer la eliminación de determinadas especialidades médicas, como señala Rojas (2020) - . Por el contrario, hay muchos aspectos positivos de la aplicación de la inteligencia artificial al ámbito de la medicina, la telemedicina y la medicina virtual. Aunque, desde luego, no podemos dejar de lado dos de los aspectos más importantes de la relación médico-paciente, como son la confianza y el contacto humano. La robotización prescinde de estos componentes humanos y los sustituye por una mayor precisión, que busca, en definitiva, la salud y el bienestar del paciente. Ello conlleva un cambio de criterio y de normativa aplicable, como hemos tenido ocasión de señalar, y también, cómo no, una adaptación del paciente en esa relación que por necesidad va a cambiar.

Desde luego, la legislación no puede estar ausente en ese cambio, y debe contemplar los instrumentos y herramientas para evitar situaciones alienantes y convertir el acto médico en uno impersonal. Por eso, la inteligencia artificial debe aplicarse con un sentido común, y paliar los efectos de deshumanización que, a priori, puede plantear la robótica en la medicina.

\section{Agradecimientos}

Trabajo elaborado en el marco del Proyecto $\mathrm{I}+\mathrm{D}+\mathrm{i}$ «Retos investigación» del Programa estatal de $\mathrm{I}+\mathrm{D}+\mathrm{i}$ orientado a los Retos de la Sociedad del Ministerio de Ciencia, Innovación y Universidades: «Contratos, transparencia y protección de datos en el mercado digital», RTI 2018-097354-B-100 (2019-2022). Sus investigadores principales son el doctor Javier Plaza Penadés, catedrático de Derecho Civil, y la doctora Luz M. Martínez Velencoso, catedrática de Derecho Civil, ambos de la Universitat de València.

Proyecto de I+D+i Retos MICINN PID2019-108710RB-Ioo (2020-2022): «Derechos y garantías frente a las decisiones automatizadas en entornos de inteligencia artificial, IoT, big data y robótica». Su investigador principal es el doctor Lorenzo Cotino Hueso, catedrático de Derecho Constitucional de la Universitat de València. 


\section{Referencias}

Aceros Gualdrón, Juan Carlos (2018). «Robots para el cuidado de personas mayores: taxonomía de una promesa». Aula: Revista de Pedagogía de la Universidad de Salamanca, 24: 43-60. DOI: 10.14201/aula2018244360.

Agencia Española de Protección de Datos (2020). Adecuación al RGPD de tratamientos que incorporan inteligencia artificial: Una introducción. Disponible en bit.ly/3pXveJB.

Anguita Ríos, Rosa María (2020). «Inteligencia artificial y derecho civil: Líneas de pensamiento en materia de daños». Revista Crítica de Derecho Inmobiliario, 96 (781): 2.541-2.581.

Atienza Navarro, María Luisa (2020). «La responsabilidad civil por daños causados por sistemas de inteligencia artificial». En Miguel Martínez Muñoz (coordinador) y Abel B. Veiga Copo (director), Retos y desafíos del contrato de seguro: Del necesario «aggiornamento» a la metamorfosis del contrato. Cizur Menor: Thomson Reuters-Civitas.

Ávila de Tomas, José Francisco, Miguel Ángel Mayer Pujadas y Víctor Julio Quesada Varela (2021). «La inteligencia artificial y sus aplicaciones en medicina II: Importancia actual y aplicaciones prácticas». Atención Primaria, 53 (1): 81-88. DOI: 10.1016/j.aprim.2020.04.014.

Balandrón, Carlos, José Gómez de Diego e Ignacio Amat Santos (2021). «Big data y nuevas tecnologías de la información: Qué necesita saber el cardiólogo». Revista Española de Cardiología, 74 (1): 81-89. DOI: 10.1016/j.recesp.2020.06.017.

BARRIO ANDRÉs, Moisés (2020). «Derecho de los robots y de la inteligencia artificial: la nueva lex robótica». En Marta Beltrán y Ofelia Tejerina Rodríguez (coordinadoras), Aspectos jurídicos de la ciberseguridad (pp. 279-306). Madrid: RA-MA.

Beltrán de Heredia Ruiz, Ignasi (2020). «Automatización y obsolescencia humana». En Agustí Cerrillo i Martínez y Miquel Peguera Poch (coordinadores), Retos jurídicos de la inteligencia artificial (pp. 113-124). Cizur Menor: Aranzadi.

Bueno OchOA, Luis (2020). «Los derechos humanos en la era de los robots (II)». En José Antonio Pinto Fontanillo y Ángel Sánchez de la Torre (editores), Los derechos humanos en el siglo XXI (pp. 45-50). Tomo 4. Madrid: Real Academia de Jurisprudencia y Legislación de España, Edisofer.

Castellanos Claramunt, Jorge (2020). «La gestión de la información en el paradigma algorítmico: inteligencia artificial y protección de datos». Métodos de Información, 11 (21): 59-82. DOI: 10.5557/IIMEI11-N21-042058.

Castellanos Claramunt, Jorge y María Dolores Montero Caro (2020). «Perspectiva constitucional de las garantías de aplicación de la inteligencia artificial: La ineludible protección de los derechos fundamentales». Ius et Scientia, 6 (2): 72-82. DOI: 10.12795/IETSCIENTIA.2020.io2.06. 
Cerdán Martínez, Vicente, María Luisa García Guardia y Graciela Padilla Castillo (2020). «Alfabetización moral digital para la detección de deepfakes y fakes audiovisuales». Cuadernos de Información y Comunicación, 25: 165-181. DOI: 10.5209/ ciyc. 68762 .

Cotino Hueso, Lorenzo (2020). «Inteligencia artificial, big data y aplicaciones contra la covid-19: Privacidad y protección de datos». Internet, Derecho y Política, 31: 1-17. DOI: 10.7238/idp.voi31.3244.

Chesney, Robert M. y Danielle Keats Citron (2019). «Deepfakes: La nueva guerra de la desinformación». Foreing Affairs: Latinoamérica, 19 (2): 85-91.

Chivato Pérez, Tomás (2019). «Impacto de las nuevas tecnologías, el big data y la inteligencia artificial en la relación médico-paciente». En Tomás Chivato Pérez y Antonio Piñas Mesa (editores), La relación médico-paciente: Claves para un encuentro humanizado (pp. 119-126). Madrid: Dykinson.

Da Silveira, Sérgio Amadeu (2020). «Responsabilidade algorítmica, personalidade eletrônica e democracia». Revista Electronica Internacional de Economia Política da Informaçao, da Comuniçao e da Cultura, 22 (2): 83-96. Disponible en bit. ly/3gpEjYH.

Del Río Solá, María Lourdes, José María López Santos y Carlos Vaquero Puerta (2018). «La inteligencia artificial en el ámbito médico». Revista Española de Investigaciones Quirúrgicas, 21 (3): 113-116. Disponible en bit.ly/35p2eB7.

Ebers, Martin (2016). «La utilización de agentes electrónicos inteligentes en el tráfico jurídico: ¿Necesitamos reglas especiales en el derecho de la responsabilidad civil?». InDret, 3: 1-22. Disponible en bit.ly/2TxqYED.

Fossaseca, Carlos A. y Pilar Moreyra (2020). «Aproximaciones a la responsabilidad civil por la utilización de inteligencia artificial y derecho de los robots: Una mirada jurídica». Revista de Responsabilidad Civil y Seguros, 8: 20-37.

García Mexía, Pablo Luis (2016). «Lex robótica y derecho digital». Revista de Privacidad y Derecho Digital, 2.

-. (2020). «Inteligencia artificial: Una mirada desde el derecho». Anales de la Academia Matritense del Notariado, 60: 117-157.

Guerris, Manel (2020). «¿Tiene ética la inteligencia artificial?». Harvard Deusto Business Review, 296: 56-58.

Lacruz Mantecón, Miguel L. (2019). «Potencialidades de los robots y capacidades de las personas». Revista General de Legislación y Jurisprudencia, 1: 85-129.

LEÓN RodRÍGUez, Hernando (2017). «Sistema macro \& micro robótico para aplicaciones médicas». Revista de Tecnología, 16 (2): 104-113. DOI: 10.18270/rt.v16i2.2524.

Lope SALVADOR, Víctor, Xhevrie Mamaqi y Francisco Javier Vidal Bordes (2020). «La inteligencia artificial: desafíos teóricos, formativos y comunicativos de la datificación». Icono 14, 18 (1): 58-88. DOI: 10.7195/ri14.v18i1.1434. 
LonCARIC, Filip, Óscar Cámara, Gemma Piella y Bart H. Bijnens (2021). «La integración de la inteligencia artificial en el abordaje clínico del paciente: Enfoque en la imagen cardiaca». Revista Española de Cardiología, 74 (1): 72-80. DOI: 10.1016/j. recesp.2020.07.012.

Martínez Devia, Andrea (2019). «La inteligencia artificial, el big data y la era digital: ¿Una amenaza para los datos personales?». La Propiedad Inmaterial, 27: 5-23. DOI: 10.18601/16571959.n27.01.

Navarro Michel, Mónica (2020). «Vehículos automatizados y responsabilidad por producto defectuoso». Revista de Derecho Civil, 7 (5): 175-223. Disponible en bit. ly/3vr2ASw.

Navas Navarro (2020). «SAlud electrónica e inteligencia ARTIFicial». En Susana Navas Navarro (Coordinadora), Salud e inteligencia artificial desde el derecho privado: Con especial atención a la pandemia por SARS-CoV-2 (covid-19) (pp. 1-51). Granada: Comares.

Peguera Poch, Miquel (2020). «En búsqueda de un marco normativo para la inteligencia artificial». En Agustí Cerrillo i Martínez y Miquel Peguera Poch (coordinadores), Retos jurídicos de la inteligencia artificial (pp. 41-56). Cizur Menor: Aranzadi.

PÉrez-Borges, Aylén (2011). «El holograma como fuente documental y recurso particular de información». Revista Española de Documentación Científica, 34 (2): 253-265. DOI: 10.3989/redc.2011.2.792.

PERIN, Andrea (2019). «Estandarización y automatización en medicina: El deber de cuidado del profesional entre la legítima confianza y la debida prudencia». Revista Chilena de Derecho y Tecnología, 8 (1): 3-20. DOI: 10.5354/0719-2584.2019.5256o.

Ramón Fernández, Francisca (2018). «Transparencia y protección de datos especialmente protegidos en genética y la salud desde el punto de vista civil y del buen gobierno». Diario La Ley: 1-15.

-. (2019). «Robótica, inteligencia artificial y seguridad: ¿Cómo encajar la responsabilidad civil?». Diario La Ley, 9.365: 1-13.

-. (2020a). «El acceso a los datos y contenidos gestionados por prestadores de servicios de la sociedad de la información de personas fallecidas: Análisis de los límites». Métodos de Información, 11 (20): 31-58. DOI: 10.5557/IIMEI11-N20-059087.

-. (2020b). «La sanidad móvil: La protección de datos referentes a la salud y la genética». En Francisca Ramón Fernández (coordinadora), Marco jurídico de la ciencia de datos (pp. 197-250). Valencia: Tirant lo Blanch.

Robles Lessa, Moyana Mariano, Hildeliza Lacerda Tinoco Boechat Cabral y Gilberto Fachetti Silvestre (2010). «Deepfake: Inteligencia artificial y algoritmo que causa riesgos a la sociedad en el ciberespacio». Derecho y Cambio social, 61: 475-487. Disponible en bit.ly/3wtkVzB. 
Rogel Vide, Carlos (2018). «Robots y personas». Revista General de Legislación y Jurisprudencia, 1: 79-90. DOI: 10.30462/RGLJ-2018-01-04-646.

RoJAs, Rafael (2020). «Inteligencia artificial vs. Inteligencia humana: ¿ serán necesarios los radiólogos en el futuro?». Radiología, 62 (1): 1-2. DOI: 10.1016/j.rx.2019.11.001.

Rojo Gallego-Burín, Marina (2020). «Los fundamentos históricos del sistema jurídico versus la personalidad electrónica de los robots». Revista Jurídica de Castilla y León, 52: 7-30. Disponible en https://bit.ly/3wvOCzU

Ruiz Hontangas, Antonio (2020). «Los retos de la inteligencia artificial y la bioética en el ámbito sanitario». Harvard Deusto Business Review, 296: 47-49.

Sánchez Navarro, María Isabel (2018). «Prótesis biónicas, biología y tecnología». Panorama Actual del Medicamento, 42 (411): 256-259. Disponible en bit. ly/3pZqUcN.

SuÁrez Gonzalo, Sara (2017). «Big social data: Límites del modelo notice and choice para la protección de la privacidad». Profesional de la Información, 26 (2): 283-292. DOI: 10.3145/epi.2017.mar.15.

Tirado Robles, Carmen (2020). «¿Qué es un robot? Análisis jurídico comparado de las propuestas japonesas y europea». Mirai: Estudios Japoneses, 4: 35-48. DOI: 10.5209/mira.67530.

\section{Sobre la autora}

Francisca Ramón Fernández es licenciada y doctora en Derecho por la Universitat de València, España. Profesora titular de Derecho Civil en la Escuela Técnica Superior de Ingeniería del Diseño (ETSID), Universitat Politècnica de València, España. Su correo electrónico es frarafer@urb.upv.es. (D) https://orcid.org/oooo-0002-0936-8229. 


\title{
REVISTA CHILENA DE DERECHO Y TECNOLOGÍA
}

La Revista de Chilena de Derecho y Tecnología es una publicación académica semestral del Centro de Estudios en Derecho Informático de la Facultad de Derecho de la Universidad de Chile, que tiene por objeto difundir en la comunidad jurídica los elementos necesarios para analizar y comprender los alcances y efectos que el desarrollo tecnológico y cultural han producido en la sociedad, especialmente su impacto en la ciencia jurídica.

\author{
EDITOR GENERAL \\ Daniel Álvarez Valenzuela \\ (dalvarez@derecho.uchile.cl) \\ SITIO WEB \\ rchdt.uchile.cl \\ CORREO ELECTRÓNICO \\ rchdt@derecho.uchile.cl \\ LICENCIA DE ESTE ARTÍCULO \\ Creative Commons Atribución Compartir Igual 4.o Internacional
}

\begin{abstract}
La edición de textos, el diseño editorial
y la conversión a formatos electrónicos de este artículo

estuvieron a cargo de Tipográfica

(www.tipografica.io).
\end{abstract}

